\title{
A partitura das emoções: a linguagem teatral na escola da infância
}

\author{
Anna Karolina Alves do Nascimento ${ }^{1}$ \\ Elaine Santana de Oliveira ${ }^{2}$ \\ Denílson Nascimento da Silva ${ }^{3}$
}

\begin{abstract}
Resumo:
O presente relato de experiência tem como objetivo refletir acerca das práticas desenvolvidas a partir dos jogos teatrais e dramáticos, de adaptações do método Rasaboxes para o teatro na perspectiva de Richard Schechner e da técnica do Alfabeto do Corpo, idealizada por Zygmunt Molik, com crianças de uma turma do 3o ano do Ensino Fundamental do Núcleo de Educação da Infância - Colégio de Aplicação da Universidade Federal do Rio Grande do Norte, tendo como referência a questão de pesquisa: Como as atrizes fazem para chorar? Como consequência dessas práticas, foi construído o extrato cênico A partitura das emoções, tendo como guia partituras corpóreo-vocais elaboradas de forma colaborativa. Nesse sentido, o processo constituiu-se como uma prática de formação de espectadores, que descentraliza o texto dramatúrgico como um ponto de partida para a experiência $\mathrm{da} /$ na linguagem teatral, ampliando o repertório vivencial e linguístico para leitura crítica e criativa de obras teatrais.
\end{abstract}

\section{Palavras-chave:}

Linguagem teatral. Infância. Formação do espectador.

\section{The score of emotions: the theatrical language in childhood's school}

\begin{abstract}
:
This present experience report aims to reflect on the practices developed from theatrical games and dramatic, adaptations of the Rasaboxes method for theater into the perspective of Richard Schech-
\end{abstract}

\footnotetext{
1 Mestre em Educação pela Universidade Federal do Rio Grande do Norte/UFRN. Foi professora substituta do Núcleo de Educação da Infância (NEI-CAp/UFRN) durante os anos de 2018 e 2019. E-mail: karolina.alvesnascimento@gmail.com ORCID iD: https://orcid.org/0000-0002-5385-8268

2 Mestre em Educação pela Universidade Federal do Rio Grande do Norte(UFRN). Docente no Núcleo de Educação da Infância (NEI-CAp/UFRN). E-mail: elainesonei@hotmail.com ORCID iD: https://orcid.org/0000-0002-4010-7449

3 Aluno do curso de Teatro (Licenciatura) da Universidade Federal do Rio Grande do Norte (UFRN). Desempenhou a função de bolsista do projeto "Linguagem teatral na escola da infância" no Núcleo de Educação da Infância (NEI-CAp/UFRN) durante 2019. E-mail: dennyssilvan@gmail.com ORCID iD: https://orcid.org/0000-0001-5553-5756
} 
ner and the technique of "Alfabeto do Corpo" (the Body Alphabet), conceived by Zygmunt Molik, with children from a 3rd grade of Elementary School of Núcleo de Educação da Infância - School of Application of the Federal University in Rio Grande do Norte/Brazil, with reference to the research question: How do actresses cry? As a consequence of these practices, it was constructed the scenic extract A partitura das emoções (The score of emotions), having as a guide body-vocal scores elaborated collaboratively. In this sense, the process constituted itself as a practice of spectator knowledge, which decentralizes the dramaturgic text as a starting point for the experience of/in the theatrical language, expanding the experiential and linguistic repertoire for critical and creative reading of theatrical works.

\section{Keywords:}

Theatrical language. Childhood. Spectator Knowledge.

\section{La partitura de emociones: la lenguaje teatral en la escuela de la infância}

\section{Resumen:}

El presente relato de experiencia tiene como objetivo reflexionar sobre las prácticas desarrolladas a partir de los juegos teatrales y dramáticos, de las adaptaciones del método Rasaboxes para el teatro en la perspectiva de Richard Schechner y la técnica de Alfabeto del Cuerpo, idealizado por Zygmunt Molik, con niños de una clase de 3er año de la Escuela Primaria del Núcleo de Educación Infantil - Escuela de Aplicación de la Universidad Federal de Rio Grande do Norte, teniendo como referencia la pregunta de investigación: ¿Cómo lloran las actrices? Como consecuencia de estas prácticas, fue construido el extracto escénico "La partitura de emociones", con partituras cuerpo-vocales como guía elaborada de forma colaborativa. En este sentido, el proceso se constituyó como una práctica de formación del espectador, que descentraliza el texto dramatúrgico como punto de partida para la vivencia del / en el lenguaje teatral, ampliando el repertorio vivencial y lingüístico para la lectura crítica y creativa de obras teatrales.

\section{Palabras clave:}

Lenguaje teatral. Infancia. Entrenamiento de espectadores.

\section{Será que elas usam cebola?}

O procedimento metodológico adotado pela equipe do NEI-CAp/UFRN (Núcleo de Educação da Infância) consiste no tema de pesquisa, o qual, de acordo com Rêgo (1999, p. 61) articula três dimensões básicas: "os conhecimentos das áreas de conteúdo que se quer tornar disponível, o contexto sociocultural das crianças, ou suas realidades imediatas, e os aspectos vinculados diretamente à aprendizagem".

Partindo dessa premissa, cada turma escolhe um ou mais temas de pesquisa a serem estudados durante o ano. Nesse contexto, as situações didáticas são pensadas de modo a favorecer o protagonismo das crianças que articulam vivências, saberes e inquietações em situações dialógicas de construção de conhecimentos.

Tendo em vista o contexto da instituição, os sujeitos da pesquisa constituem a turma do $3^{\circ}$ ano matutino do ano de 2019, composta por 21 crianças com idade entre 8 e 9 anos. Dentre elas, 7 meninos e 14 meninas, sendo uma das crianças com baixa visão e, portanto, público-alvo da educação especial. O tema de pesquisa escolhido pela turma através de votação foi profissões. Apesar da amplitude do tema, o trabalho pedagógico desenvolveu-se a partir das questões de estudo sugeridas pelas crianças e das ideias iniciais que elas tinham sobre ele. 
Dentre as perguntas elaboradas pelas crianças no estudo da realidade do tema de pesquisa, momento em que elas colocam suas hipóteses iniciais e suas dúvidas sobre o tema a ser estudado, podemos destacar: "Como o cozinheiro faz comida sem se queimar e que cuidados ele deve ter?"; "Como os artistas que pintam descobrem as suas técnicas?" e, a principal questão para as nossas reflexões, no limite desse relato de experiência: “Como as atrizes fazem para chorar?". Partindo dessa última inquietação, construímos o plano de trabalho da disciplina de artes, com ênfase na linguagem teatral, para o segundo semestre.

Para desconstruir algumas ideias iniciais tais como: "Elas usam cebola" ou "Elas usam cristal chinês", propusemos a exploração das emoções, criando situações favoráveis para que as crianças experimentassem e descobrissem no corpo os pontos de ativação do estado dessas emoções, diferenciando a sensação/estado do sentimento em si.

Desse modo, preocupando-se então com o acesso linguístico do teatro, o objetivo da prática teatral desenvolvida com a turma voltou-se para um processo de formação de espectadores. Nesse sentido, convém diferenciar processos de formação de público de processos de formação de espectadores, apoiados em Desgranges (2011).

Segundo o autor, o processo de formação de público é da ordem do acesso físico ao teatro, de modo a facilitar a frequentação de espetáculos e aumentar o interesse nessa arte. Algumas das estratégias para alcançar esse propósito são o desconto nos ingressos, a divulgação e a disponibilização de transporte. Atuando em outra perspectiva, o processo de formação de espectadores oportuniza o acesso linguístico ao teatro, de modo que as crianças possam interagir dialogicamente com as obras, fazendo leituras de forma autônoma, crítica e criativa.

Tendo em vista uma formação de espectadores que desperte o desejo pelo teatro, Desgranges (2011, p. 159) afirma que "pode ser conveniente instaurar um processo pedagógico que possibilite aos espectadores em formação, a apropriação da linguagem teatral. Um processo em que a fome de teatro seja despertada pelo próprio prazer da experiência.".

Esse prazer na experiência prescinde uma postura ativa na/da linguagem teatral, tendo em vista que o ato do espectador

não se resume ao recolhimento de informações, ou a decodificação de enunciados, ou ao entendimento de mensagens, pois a experiência estética se realiza como constituição de sentidos. O que solicita invenção na linguagem, ou invenção de linguagem. O papel do leitor em arte, assim concebido, muito se aproxima do próprio papel do escritor. (DESGRANGES, 2010, p. 51, grifo nosso).

Atuando nas duas frentes, o NEI-CAp/UFRN tem realizado ações voltadas para o acesso físico e linguístico da arte teatral. Nesse sentido, apesar dos limites orçamentários, buscamos que, anualmente, as crianças assistam a um espetáculo infantil, número que almejamos ampliar. No que tange a formação linguística, a prof ${ }^{a}$. Dra. Uiliete Pereira ${ }^{4}$ coordena o projeto de extensão Linguagem teatral na escola da infância. A iniciativa proporcionou que a instituição tivesse um bolsista do curso de Licenciatura em Teatro da UFRN, mediando, juntamente com as professoras pedagogas responsáveis pelas turmas, práticas teatrais tanto na educação infantil quanto no ensino fundamental.

Inserido nesse contexto, esse relato de experiência objetiva refletir acerca das práticas teatrais desenvolvidas a partir dos jogos teatrais e dramáticos, do método Rasaboxes e da técnica do "Alfabeto do Corpo", com crianças de uma turma do $3^{\circ}$ ano do ensino fundamental do NEI-CAp/UFRN, tendo como referência a questão de pesquisa: Como as atrizes fazem para chorar?

4 Doutora e Mestre em Educação pela Universidade Federal do Rio Grande do Norte (UFRN). Professora do NEI-CAp/UFRN. 


\section{Jogando com as emoções}

Durante o segundo semestre de 2019, nas aulas de teatro, trabalhamos, sobretudo, com a prática de jogos teatrais e dramáticos, sendo esses improvisacionais ou não. A metodologia baseou-se, portanto, em um processo híbrido, valendo-se de práticas advindas de diferentes contextos. Entretanto, de acordo com Maria Lúcia Pupo (2005, p. 227), a noção de jogo teatral e de jogo dramático (na acepção francesa), apresentam vários pontos de convergência, visto que ambos são vinculados

a uma perspectiva de renovação do teatro, têm sua origem marcada também por um engajamento de caráter social. Prescindem da noção de talento ou de qualquer pré-requisito anterior ao próprio ato de jogar; consideram que a disponibilidade para a experiência e o caráter coletivo do trabalho são pontos centrais no processo de aprendizagem. (PUPO, 2005, p. 227).

Partindo então de metodologia híbrida, mas com pontos de convergência que validam seu uso de forma articulada, pretendemos ressaltar agora as características de cada tipo de jogo. Os jogos teatrais foram concebidos nos Estados Unidos, a partir dos anos 1960, pela professora, atriz e diretora de teatro Viola Spolin. Para a autora, o jogo é definido como uma "atividade aceita pelo grupo, limitada por regras e acordo grupal; divertimento; espontaneidade, entusiasmo e alegria [...] seguem par e passo com a experiência teatral." (SPOLIN, 2005, p. 342).

Nesse sentido, tomando por base as regras e calcado na improvisação, esse sistema pressupõe que existam no mínimo dois grupos, aquele que joga em uma situação improvisada e aquele que participa enquanto espectador, tendo em vista analisar criticamente a encenação de modo a contribuir com o primeiro grupo. Em seguida, existe uma alternância de posição entre os grupos.

A experimentação cênica das crianças, apesar de improvisada, não é elaborada ao acaso, mas sempre voltada para um foco, ou seja, para o ponto de concentração do problema proposto pelo mediador. O foco varia de acordo com as investigações do grupo, podendo ser "mostrar onde os personagens estão", "manipular um objeto imaginário", "relacionar-se com os espectadores", entre muitos outros, desde que possibilite a aprendizagem do aspecto da linguagem que está sendo estudado. A norma básica desse sistema de jogos, consiste então em

Propor problemas para resolver problemas, [...] em que a definição de problema cria, por um lado, um ponto de concentração único e claro para o grupo, tanto para os jogadores em cena quanto para os que observam, e, por outro, organiza um esquema de jogo em que não há uma única resposta possível, e nem certo ou errado. Existem sim infinitas possibilidades a serem experimentadas, o que deixa o grupo todo envolvido na criação de resoluções cabíveis, nunca definitivas. Trabalhar em função do foco estimula, portanto, uma ação conjunta. (DESGRANGES, 2011, p. 114).

O conceito francês de jogo dramático (jeu dramatique ${ }^{5}$ ), por sua vez, é caracterizado por "uma atividade grupal, em que o indivíduo elabora por si e com outros as criações cênicas, valendo-se das apresentações no interior das oficinas como um meio de investigação e apreensão da linguagem teatral" (DESGRANGES, 2011, p. 95). Durante o jogo dramático atua-se no desenvolvimento de habilidades expressivas e analíticas, tendo em vista que as crianças procuram dizer algo através da linguagem teatral, ao passo que também exercitam a leitura da heterodiscursividade cênica, ou seja, dos diversos signos nos quais essa linguagem se constrói.

5 “O termo é cunhado na França nos anos 30 e tem a assinatura de Léon Chancerel (1886-1965), notório homem de teatro que está também na origem do teatro infantil naquele país." (PUPO, 2005, p. 224). 
Nesse contexto, tanto o jogo teatral quanto o dramático, mostram-se promissores porque relativizam radicalmente o texto como aspecto central do teatro. As crianças, então, são encorajadas por meio da prática, a uma

leitura transversal dos espetáculos, percebendo que não apenas o texto tem algo a comunicar numa encenação (leitura horizontal), mas como a arte teatral se vale de diversos signos que, justapostos, formam como que uma página cravada no espaço, que se renova a cada instante. (DESGRANGES, 2011, p. 163).

De modo a avaliar continuamente, assim como propor uma postura ativa dos jogadores-espectadores, ao final de cada aula realizávamos uma roda de conversa. O processo de avaliação nas práticas teatrais motivadas pelo jogo, portanto, está "sempre estreitamente vinculada à solução de problemas de ordem teatral a ser resolvidos por quem atua, assegura[ando] também outra importante aprendizagem: a da leitura da representação" (PUPO, 2015, p. 35).

O primeiro jogo desenvolvido foi o Casulo. Nele, as crianças ficam espalhadas pelo espaço da sala agachadas no chão como se fossem um casulo de borboleta, até que um "monstro" passa por cima de uma delas e a desperta. A partir de então, o casulo passa a ser o monstro, e o monstro passa a fugir, até que pule por cima de outro casulo e o desperte. Depois de um tempo jogando, inserimos a variação da fuga com uma emoção. Nesse momento, a criança deveria fugir do monstro com alegria, medo, tristeza ou raiva, a depender da orientação do mediador.

Percebemos, então, muitas representações estereotipadas do que eram essas emoções. Tendo em vista a desconstrução dessas caricaturas, apresentamos para as crianças o método do Rasaboxes, adaptado para o teatro por Richard Schechner, que coloca o ator como o atleta das emoções e o auxilia a investigar a expressividade corporal e os pontos de ativação desses estados de emoções no corpo. De acordo com Minnick e Cole (2011, p. 4), o princípio básico do método "é o de que cada ideia que um ator deseja comunicar deve, de alguma forma, ser incorporada, recebida por e expressa no, ou através do corpo, mesmo que seja apenas no nível da respiração".

Para o exercício escolhido, fizemos uma grade no chão utilizando fita adesiva, criando nove retângulos/caixas. Cada uma delas trazia uma emoção como ponto de partida, e no decorrer do jogo, o ator transitava entre todas. Entre as emoções temos: amor, alegria, tristeza, raiva, medo, nojo, surpresa, coragem/heroísmo. Na proposta tradicional, a caixa central é vazia, destinada à neutralidade, uma possibilidade de desapego das outras emoções. Entretanto, adaptamos a abordagem, nomeando a caixa central de encantamento.

Fotografia 1

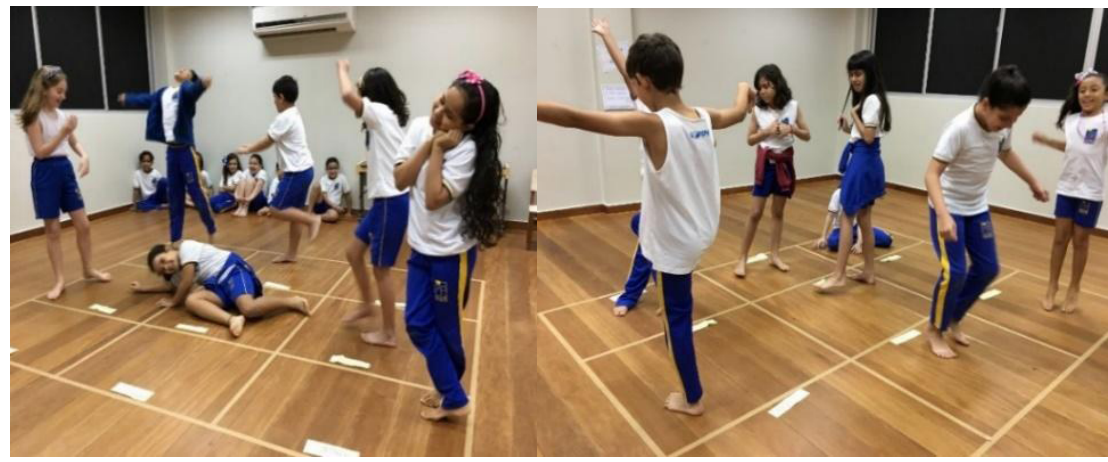

Fonte: Elaborado pelos autores.

Legenda: As crianças exploram o método Rasaboxes transitando pelas emoções em diferentes caixas.

A partir dessas emoções, as crianças poderiam utilizar da respiração ou da lembrança da sensação de um acontecimento que as fez sentir determinada emoção. Buscamos sempre deixar claro que o que precisávamos era da sensação da emoção e não do sentimento em si. Notamos, 
nesse momento, que algumas crianças apresentavam dificuldades em expressar algumas emoções, necessitando de um maior incentivo para lembrar de sensações ou mobilizar a respiração.

$\mathrm{Na}$ aula seguinte, tendo em vista a continuação do trabalho, vivenciamos outro exercício inspirado no Rasaboxes. Dessa vez, em duplas, uma de frente para outra, transitando pelas emoções que na oportunidade estavam dispostas em um papel no chão, as crianças falariam o seguinte diálogo: "Você viu o pato?" "Pato? Que pato?" "O pato!" "Sim, o pato!".

Em seguida, mediamos o exercício do coro e corifeu. Nele, solicita-se que o corifeu, líder do grupo, faça uma ação que deve ser copiada pelas demais crianças, as quais constituem o coro. Contextualizamos para as crianças o contexto histórico dessas figuras, tendo que vista que, a

origem do teatro grego - e com ele, da tradição do teatro ocidental - confunde-se com as celebrações ritualísticas de um grupo no qual dançarinos e cantores formam, ao mesmo tempo, público e cerimônia. A forma dramática mais antiga seria a recitação do corista principal interrompida pelo coro. (PAVIS, 1999, p. 73).

Nesse sentido, de acordo com Santos, Lorenzoni e Nunes (2018, p. 12) nos ritos para homenagear o deus Dionísio, celebrando a fertilidade na terra, havia

um grupo de pessoas que se manifestava de forma improvisada, esse grupo conhecido como Ditirambo, que imitava e declamava poesias. Essa imitação era feita por um coro e um solista (chamado do corifeu que comandava o coro) que segundo Aristóteles deu origem à Tragédia.

As crianças criaram partituras corporais, nas quais mais tarde foram adicionados os haicais ${ }^{6}$ de Paulo Leminski, explorando as emoções. O coro teria que fazer os mesmos movimentos e falar o texto exatamente da mesma forma que o corifeu. O gênero textual haicai foi escolhido por favorecer a combinação da improvisação física com a experimentação vocal, com o intuito de unificá-las.

Seguindo com o plano de trabalho, sentimos a necessidade de expandir o repertório de ações das crianças. Pensando nessa perspectiva, trouxemos a técnica do Alfabeto do Corpo, idealizada pelo ator, diretor e pedagogo polonês Zygmunt Molik. Nela, são propostas aproximadamente 30 ações, a partir das quais constrói-se um tipo de linguagem corporal (CAMPO, 2012).

Tendo em vista propor ações para que as crianças realizassem, fizemos um recorte e algumas adaptações das ações do "Alfabeto do Corpo" e levamos para as crianças: apontar, puxar, empurrar, lançar, amassar, flutuar, caminhar sobre pedras no rio, rotação de ombros, pegar pedrinhas no chão, tocar o céu e pedalar sobre as nuvens. A proposta foi fazer com que as crianças experimentassem essas ações com cem por cento do movimento, e depois em outras porcentagens, até chegar somente na intenção de fazê-las.

Concomitantemente, enviamos como atividade de casa uma seleção com 21 haicais do livro Os Hai-kais do menino maluquinho (ZIRALDO, 2013), para que cada criança escolhesse o que mais lhe agradasse e fizesse uma ilustração. Para a atividade, não haveria restrições se duas ou mais crianças escolhessem os mesmos versos. Logo após a atividade, a partir das ações do "Alfabeto do Corpo" e dos haicais escolhidos, as crianças criaram partituras corpóreo-vocais individuais. Durante esse processo, retomamos as intenções das emoções exploradas no início do trabalho.

6 Poemas curtos de três versos. O gênero discursivo tem origem no Japão. 


\section{A grande partitura}

A partir do escopo de jogos realizados, assim como das partituras corpóreo-vocais coletivas e individuais criadas, a segunda etapa do plano de trabalho deu-se com a construção de uma dramaturgia, juntamente com as crianças, que pudesse mostrar o processo desenvolvido durante as aulas-teatro.

Assim, nasceu o extrato cênico intitulado A partitura das emoções. Ele foi apresentado durante a VI Mostra Cultural e II Feira Gastronômica do NEI-CAp/UFRN. No evento, os espectadores eram constituídos por crianças, pais e professores da instituição, assim como de escolas visitantes.

O roteiro do extrato é composto pela "caminhada das emoções", momento no qual as crianças andam pelo espaço cênico com o corpo neutro ao som da versão instrumental de Alegria (Cirque du Soleil), até que, motivados por sinais sonoros, param e começam a expressar através do corpo as emoções, cada uma em seu tempo.

Em seguida, ainda ocupando todo o espaço, as crianças começam, uma de cada vez, a realizar suas partituras individuais, repetindo-as duas vezes e, em seguida, deitando-se no chão. Aquelas que haviam escolhido o mesmo haicai, fazem ao mesmo tempo, ainda que com partituras diferentes.

Ao som de Transfiguração (Cordel do Fogo Encantado), o grupo começa a se levantar aos poucos, constituindo um "bolinho". Duas crianças, cada uma em um sentido, começam a correr ao redor desse amontoado de emoções para que elas se transfigurem para a cena final do extrato.

As crianças dividem-se em três grupos, formando um " $U$ " no palco, ou seja, dois grupos localizados nas laterais, um em frente ao outro e o terceiro ao fundo da área de apresentação. Enquanto a versão instrumental de Believer (Imagine Dragons) toca, os grupos, paulatinamente começam a realizar suas partituras, mas sem a parte vocal. A partir de intervenções sonoras cada grupo tem seu momento de apresentar sua partitura, agora acompanhada da voz, duas vezes. $\mathrm{O}$ extrato cênico finaliza com as crianças retornando ao "bolinho", novamente ao som de Transfiguração, até que este, "explode"!

\section{O espectador em plena transfiguração}

O teatro vale-se de um palco heterodiscursivo, no qual vários elementos são dotados de significado. Além do texto, o figurino, a iluminação, os objetos cênicos, o corpo, as sonoridades etc., propõem desafios de interpretação aos espectadores. Entendemos que, para a leitura de uma linguagem tão diversa, é necessário que o espectador seja formado, ou seja, que se aproprie dessa linguagem, conquistando sua autonomia interpretativa. Nesse sentido, o conhecimento de mundo de cada criança, apesar de essencial para a dialogia com a cena, não é o bastante, demandando um processo educativo intencional para ampliar as possibilidades de compreensão de cena.

Tal formação não pode ser desvinculada de uma prática na/da linguagem, tendo em vista superar análises laudatórias que visam somente a identificação e não a provocação estética. Busca-se o ato que é autoral, e que, por ser vivenciado, provoca o espectador a fazer uma análise mais embasada daquilo que assiste (ou da qual participa).

Sabe-se que existem várias práticas que podem levar as atrizes a chorar. Nossa intenção, enquanto mediadores, não foi levar as crianças as lágrimas, mas sim, desmistificar o uso da cebola e/ou cristal chinês e motivar uma ambiência favorável à experiência na linguagem teatral que, longe de ser pautada na égide da tristeza, pudesse ampliar as sensações vivenciadas pelas crianças. Desse modo, o questionamento da turma foi deflagrador de um plano de trabalho, voltado para as emoções e seus pontos de ativação, visando principalmente diferenciar a sensação do sentimento propriamente dito. 
Nesse sentido, o processo constituiu-se como uma prática de formação de espectadores, que descentraliza o texto dramatúrgico como ponto de partida para uma experiência da/na linguagem teatral, ampliando o repertório vivencial e linguístico para leitura crítica e criativa de obras teatrais.

\section{Referências}

CAMPO, Giuliano. Trabalho de voz e corpo de Zygmunt Molik: o legado de Jerzy Grotowski. 1. ed. São Paulo: É Realizações, 2012.

DESGRANGES, Flávio. Arte como experiência da arte. Lamparina: Revista de Ensino de Teatro, Belo Horizonte, v. 1, n. 1, p. 50-56, jun. 2010.

DESGRANGES, Flávio. A pedagogia do teatro: provocação e dialogismo. 3. ed. São Paulo: Hucitec, 2011.

MINNICK, Michele; COLE, Paula Murray. O ator como atleta das emoções: o Rasaboxes. O Percevejo online, Rio de Janeiro, v. 3, n. 01, p. 1-25, jan./jul. 2011. Disponível em: http://www.seer.unirio.br/index.php/opercevejoonline/article/ view/1797/1460. Acesso em: 12 set. 2019.

PAVIS, Patrice. Dicionário de Teatro. 1. ed. São Paulo: Perspectiva, 1999.

PUPO, Maria Lúcia de Souza Barros. Para desembaraçar os fios. Educação \& Realidade, Porto Alegre, v. 30, n. 2, p. 217-228, jul./dez. 2005.

PUPO, Maria Lúcia de Souza Barros. Para alimentar o desejo de teatro. 1. ed. São Paulo: Hucitec, 2015.

RÊGO, Maria Carmem Freire Diógenes. O currículo em movimento. Caderno Faça e Conte, Natal, ano 2, v. 2, n. 2, p. 61-82, jul./dez. 1999.

SANTOS, Camila Borges dos; LORENZONI, Cândice Moura; NUNES, Lúcia de Fátima Royes. Jogo Teatral. 1. ed. Santa Maria: UFSM: NTE, 2018. Disponível em: https://www.ufsm.br/app/uploads/sites/358/2019/06/Jogo-Teatral_Finalizado_ISBN.pdf. Acesso em: 11 set. 2019.

SPOLIN, Viola. Improvisação para o Teatro. Tradução e revisão de Ingrid Dormien Koudela e Eduardo José de Almeida Amos. São Paulo: Perspectiva, 2005.

ZIRALDO. Os Hai-kais do menino maluquinho. 1. ed. São Paulo: Editora Melhoramentos, 2013.

Data de submissão: 20/01/2021

Data de aceite: 14/04/2021 